\title{
Metabolic responses to high-fat diets rich in $n-3$ or $n-6$ long-chain polyunsaturated fatty acids in mice selected for either high body weight or leanness explain different health outcomes
}

Karin Nuernberg ${ }^{1}$, Bernhard H Breier ${ }^{2}$, Shakeela N Jayasinghe ${ }^{3}$, Hannes Bergmann ${ }^{4}$, Nichola Thompson ${ }^{5}$, Gerd Nuernberg ${ }^{6}$, Dirk Dannenberger ${ }^{1}$, Falk Schneider ${ }^{7}$, Ulla Renne ${ }^{6}$, Martina Langhammer ${ }^{6}$ and Korinna Huber ${ }^{4^{*}}$

\begin{abstract}
Background: Increasing evidence suggests that diets high in polyunsaturated fatty acids (PUFA) confer health benefits by improving insulin sensitivity and lipid metabolism in liver, muscle and adipose tissue.

Methods: The present study investigates metabolic responses in two different lines of mice either selected for high body weight (DU6) leading to rapid obesity development, or selected for high treadmill performance (DUhTP) leading to a lean phenotype. At 29 days of age the mice were fed standard chow (7.2\% fat, 25.7\% protein), or a high-fat diet rich in n-3 PUFA ( $n-3$ HFD, 27.7\% fat, 19\% protein) or a high-fat diet rich in $n-6$ PUFA (n-6 HFD, 27.7\% fat, $18.6 \%$ protein) for 8 weeks. The aim of the study was to determine the effect of these PUFA-rich high-fat diets on the fatty acid profile and on the protein expression of key components of insulin signalling pathways.

Results: Plasma concentrations of leptin and insulin were higher in DU6 in comparison with DUhTP mice. The high-fat diets stimulated a strong increase in leptin levels and body fat only in DU6 mice. Muscle and liver fatty acid composition were clearly changed by dietary lipid composition. In both lines of mice n-3 HFD feeding significantly reduced the hepatic insulin receptor $\beta$ protein concentration which may explain decreased insulin action in liver. In contrast, protein kinase $C \zeta$ expression increased strongly in abdominal fat of n-3 HFD fed DUhTP mice, indicating enhanced insulin sensitivity in adipose tissue.

Conclusions: A diet high in n-3 PUFA may facilitate a shift from fuel deposition in liver to fuel storage as fat in adipose tissue in mice. Tissue specific changes in insulin sensitivity may describe, at least in part, the health improving properties of dietary n-3 PUFA. However, important genotype-diet interactions may explain why such diets have little effect in some population groups.
\end{abstract}

Keywords: polyunsaturated fatty acids, high fat diet, metabolic response, mice, selection line

\section{Background}

Obesity has increased at an alarming rate over the past few decades, affecting a large population worldwide. Major medical complications including type 2 diabetes and cardiovascular disease are clearly linked with obesity and are increasing public health concerns [1,2]. The complex pathogenesis of obesity and type 2 diabetes is

\footnotetext{
* Correspondence: korinna.huber@tiho-hannover.de

${ }^{4}$ Department of Physiology, University of Veterinary Medicine Hannover,

30173 Hannover, Germany

Full list of author information is available at the end of the article
}

influenced by both genetic and environmental variables [3]. One of the most important contributing factors of obesity and associated metabolic complications is a diet of high caloric density which promotes excessive body weight gain [4]. The high saturated fat content of the Western diet is considered to be at least in part responsible for the perturbations in energy regulation observed in many obese individuals $[1,4]$.

In addition to the total calorie intake from dietary fat, mounting evidence suggests that the absolute and relative intake of specific $n-6$ and $n-3$ long-chain polyunsaturated

\section{C) Biomed Central}


fatty acids (PUFA) contribute to the metabolic outcome [5]. Furthermore, specific dietary lipids can individually influence metabolic pathways, changing the plasma lipid profile and gene expression [6-8]. Recent studies have shown that increasing saturated fatty acids in an obesogenic high-fat diet (HFD) significantly impairs insulin sensitivity in liver, skeletal muscle, heart muscle and adipose tissue in rodents [9-15]. Furthermore, diets rich in n-6 PUFA may promote abdominal obesity, possibly by increasing sterol regulatory element binding protein 1c (SREBP1c) in visceral adipose tissues of rats, thereby stimulating lipogenic pathways [16]. Conversely, it has been proposed that diets rich in $n-3$ PUFA had anti-obesogenic effects and lead to a decrease in fat deposition and fasting serum triglyceride concentrations concomitant with an increase in energy expenditure and fatty acid oxidation in human and rodent studies $[17,18]$. Dietary lipids are also known to influence tissue fatty acid composition which is linked with changes in tissue function. For example, PUFA are important constituents of the lipid bilayer, enhancing membrane fluidity of cells and modifying cellular processes in rodents $[19,20]$. Therefore, dietary fatty acids play important roles in the structural composition of cells as well as in the signalling functions of specific cellular processes.

Obesity is also influenced by genetic factors. It is clear that obesity runs in families and the pattern of inheritance of obesity strongly suggests that the effect is polygenic, with each variant of many different genes making a small contribution to the outcome $[21,22]$. However, the strong environmental effects that are observed have led to the notion that obesity is the result of an interaction between a genetic predisposition and environmental influences, although the specific biological nature of these interactions requires further investigation. Mice from long-term selection experiments offer unique models to examine the contributions of genetic factors in determining specific dietary influences on metabolic regulation relevant to obesity development. Mice lines with biologically distinct traits, of an "energy storage phenotype", the high body weight line (DU6); and of an "energy usage phenotype", the high treadmill performance line (DUhTP), were generated by long-term selection from a common genetic pool of outbred mice [23-25]. The nature of the high body weight gain and obesity development in DU6 mice is polygenic and appears to be linked to several quantitative trait loci on distinct chromosomes contributing to higher body weight, increased fat accumulation and metabolic changes [25-27]. Although the genetic basis of leanness in DUhTP mice has not been established, their phenotypic characteristics include lower body weight, reduced food intake and smaller fat depots [23,24]. There is also expanding research evidence that selection of muscle performance is commonly based on multiple gene polymorphisms [28-30].

The aim of the present study was to investigate the fatty acid composition of tissues, and the metabolic responses to high-fat diets rich in either $n-3$ or $n-6$ PUFA in mice, with a known predisposition for high body weight or leanness. The study also investigates whether different metabolic responses may be linked to changes in insulin signalling pathways in liver, muscle and abdominal adipose tissue. Therefore, it is hypothesised that mice selected for either high body weight or leanness show different responses in lipid metabolism and alterations in insulin effectiveness. To test this hypothesis, we examined the effect of $n-3$ PUFA and $n-6$ PUFA rich high-fat diets on body weight, fatty acid composition, metabolic regulation and insulin signalling pathways in liver, muscle and adipose tissue of mice selected for either high body weight or for high running performance. The work presented here advances our understanding of the metabolic responses to high-fat diets rich in $n-3$ and n-6 PUFA and whether changes in insulin action and/or lipid metabolism in liver, muscle and adipose tissue may be involved. Different genetic predispositions (e.g. for leanness or obesity) could favour specific metabolic pathways in the down-stream effects on lipid or carbohydrate metabolism and influence the health outcome.

\section{Materials and methods \\ Animals}

In total 60 male mice of two different selection lines and three dietary treatments were included in this study. The selection of mice was based on traits for either high body weight or high endurance fitness and was performed at the Leibniz Institute in Dummerstorf (DU lines). The high body weight line (DU6) was selected for high body weight at day 42 (6 weeks) of life over 128 generations [25]. The high treadmill performance line (DUhTP) was selected for high treadmill performance measured by a computer-controlled treadmill at day 70 of life for 95 generations [23,24]. Thirty mice of each selected line were subdivided in 3 feeding groups with 10 mice per group. The isocaloric high-fat diets (HFD) were enriched either with $n-3$ PUFA (27\% fish oil, $n-3 / n-6$ (quotient $6.2)$; -3 HFD) or with $n-6$ PUFA (27\% sunflower oil, $n-3 / n-6$ (quotient 0.0062 ); n-6 HFD). The control group was fed with standard mice chow (Altromin, Lage Germany; $7 \%$ fat; standard chow). The composition of the different diets is presented in Table 1 . The control diet had a higher crude protein content compared to the high-fat diets. Each animal was kept individually in a cage equipped with wooden shavings and with free access to water. From birth until the $28^{\text {th }}$ day of life all animals were fed with the standard chow diet. From the $29^{\text {th }}$ until 
Table 1 Composition of the standard chow and the PUFA-rich high-fat diets

\begin{tabular}{|c|c|c|c|}
\hline & $\begin{array}{c}n-3 \\
\text { HFD }\end{array}$ & $\begin{array}{c}n-6 \\
\text { HFD }\end{array}$ & $\begin{array}{l}\text { Standard } \\
\text { chow }\end{array}$ \\
\hline Crude protein (\%/DM) & 19.0 & 18.6 & $25 \cdot 7$ \\
\hline Crude fat (\%/DM) & $27 \cdot 4$ & $27 \cdot 7$ & $7 \cdot 2$ \\
\hline Crude ash (\%/DM) & $5 \cdot 1$ & $5 \cdot 0$ & $8 \cdot 1$ \\
\hline Metabolisable energy (MJ/DM) & $20 \cdot 5$ & $20 \cdot 6$ & $15 \cdot 9$ \\
\hline \multicolumn{4}{|l|}{ Fatty acid composition (wt \%) } \\
\hline Myristic acid (C14:0) & $6 \cdot 3$ & 0.4 & $0 \cdot 8$ \\
\hline Palmitic acid (C16:0) & $14 \cdot 7$ & $6 \cdot 1$ & $13 \cdot 2$ \\
\hline Stearic acid (C18:0) & $2 \cdot 9$ & 3.7 & $2 \cdot 8$ \\
\hline Oleic acid (C18:1cis-9) & $14 \cdot 3$ & $22 \cdot 5$ & $20 \cdot 6$ \\
\hline Linoleic acid (C18:2n-6) & 4.9 & $64 \cdot 4$ & $54 \cdot 1$ \\
\hline$\alpha$ Linolenic acid (C18:3n-3) & 7.0 & $0 \cdot 1$ & 4.5 \\
\hline Arachidonic acid (C20:4n-6) & 0.6 & n.a. & n.a. \\
\hline Eicosapentaenoic acid (C20:5n-3) & $12 \cdot 3$ & $0 \cdot 2$ & 0.2 \\
\hline $\begin{array}{l}\text { Docosapentaenoic acid (C22:5n- } \\
\text { 3) }\end{array}$ & $2 \cdot 1$ & 0.01 & 0.05 \\
\hline Docosahexaenoic acid (C22:6n-3) & $16 \cdot 0$ & 0 & 0.04 \\
\hline$\Sigma n-3 F A$ & 39.9 & 0.4 & 4.9 \\
\hline$\Sigma n-6 F A$ & $6 \cdot 4$ & $64 \cdot 4$ & $54 \cdot 2$ \\
\hline
\end{tabular}

Fatty acid content is given in weight (wt) \%; n.a. not analysed DM-dry matter; PUFA-polyunsaturated fatty acids; FA-fatty acids; HFD-high fat diet.

the $87^{\text {th }}$ day, animals were either allocated to one of the high-fat diets or were kept continuously on the standard chow. All diets were provided ad libitum. Body weight was recorded weekly until the end of the experiment. Mean food intake was determined weekly for each animal. Daily food intake, food intake per g metabolic body weight (bwt ${ }^{0.75}$ ) and daily calorie intake per $\mathrm{g} \mathrm{bwt}^{0.75}$ were calculated for all experimental groups. All animal procedures were approved by the local animal welfare authority (Reg.-No. LALLF M-V/TSD/7221.3-2.1-011/06).

\section{Tissue and blood sample collection}

At the end of the study at day 87 , the animals were killed by cervical dislocation and trunk blood samples were collected after decapitation. Liver, quadriceps femoris muscle and abdominal adipose tissue were dissected immediately and were weighed, snap frozen in liquid nitrogen and stored at $-80^{\circ} \mathrm{C}$ until analysis. Analyses were performed within one year after sampling. EDTA blood was centrifuged at $2750 \mathrm{~g}$ at $4^{\circ} \mathrm{C}$ for 5 minutes. Plasma was removed, centrifuged again and stored at $-20^{\circ} \mathrm{C}$ for future analysis.

\section{Plasma analyses}

Plasma leptin was measured by a commercial sandwichtype ELISA (DSL, Webster, Texas, U.S.A.). The sensitivity (minimum detection limit) was $0.3 \mathrm{ng} / \mathrm{ml}$. The coefficient of intra-assay variation was $5.9 \%$, the coefficient of inter-assay variation was $7.2 \%$. The plasma insulin levels were measured by a commercial radioimmunoassay (RIA) (sensitive rat RIA, Linco, St. Charles, Missouri, U.S.A.). The coefficient of intra-assay variation was $5.5 \%$, the coefficient of inter-assay variation was $8.6 \%$. Total cholesterol, free fatty acids and glucose concentrations were analysed using a COBAS MIRA Chemistry Analyzer (Roche, Switzerland) and respective test kits. Total cholesterol was determined by colorimetric measurements with end point detection of cholesterol oxidase, phenol, aminoantipyrin (CHOD-PAP) (Labor und Technik Lehmann, Berlin, Germany). Free fatty acids were determined by colorimetric and enzymatic measurements (RANDOX, Crumlin, UK). Plasma glucose was determined by colorimetric measurements of glucose-oxidase, phenol, aminoantipyrin (GOD-PAP) (Labor und Technik Lehmann, Berlin, Germany).

\section{Determination of fatty acid composition}

Samples of livers (0.4-0.6 g) and quadriceps femoris muscles (0.04-0.07 g) were thawed at $4^{\circ} \mathrm{C}$. After homogenisation (Ultra Turrax, IKA Staufen, Germany; T25, $3 \times$ $15 \mathrm{sec}, 12,000 \mathrm{rpm}$ ) and adding C19:0 as an internal standard, the total lipids were extracted in duplicates with chloroform/methanol (2:1, v/v) at room temperature. All the solvents contained $0.005 \%(\mathrm{w} / \mathrm{v})$ of t-butylhydroxytoluene in order to avoid oxidation of PUFA. The extraction mixture was stored at $5^{\circ} \mathrm{C}$ for $18 \mathrm{~h}$ in the dark and subsequently washed with $0.02 \%$ aqueous $\mathrm{CaCl}_{2}$. The organic phase was dried with $\mathrm{Na}_{2} \mathrm{SO}_{4}$ and $\mathrm{K}_{2} \mathrm{CO}_{3}$ (10:1, $\mathrm{wt} / \mathrm{wt}$ ) and the solvent was subsequently removed under nitrogen at room temperature. The lipid extracts were re-dissolved in toluene and $3 \mathrm{mg}$ (muscle) to $20 \mathrm{mg}$ (liver) was used for methyl ester preparation. Fatty acids of liver and muscle were determined by gas chromatography as previously described by Dance et al. [31]. Delta-9 desaturase index was calculated by the following equation $((\mathrm{C} 14: 1+\mathrm{C} 16: 1+\mathrm{C} 18: 1+\mathrm{C} 17: 1) /(\mathrm{C} 14: 1+\mathrm{C} 16: 1+\mathrm{C} 18: 1$ $+\mathrm{C} 17: 1+\mathrm{C} 14: 0+\mathrm{C} 16: 0+\mathrm{C} 17: 0+\mathrm{C} 18: 0)) \times 100=\Delta 9$. This index largely reflects desaturase activity.

\section{Tissue sample preparation}

Liver, quadriceps femoris muscle and abdominal adipose tissue samples were homogenised in ice-cold RIPA lysis buffer (Triton X-100, sodium dodecyl sulphate, sodium chloride, Tris- $\mathrm{HCl}$, deoxycholic acid, sodium orthovanadate, and Complete Mini EDTA-free protease inhibitors from Roche, Diagnostics) and stored at $-80^{\circ} \mathrm{C}$ until analysis. Protein concentrations of the liver and muscle homogenates were determined using a Bradford assay.

Western blotting was performed as described earlier [32]. In short, SDS-PAGE was performed using $8 \%$ separation gels. Proteins were transferred onto nitrocellulose membranes by tank blotting, blocked with fat-free milk (5\%) overnight (or for $2 \mathrm{~h}$ at RT for protein kinase 
$\mathrm{C}$ zeta (PKC $\zeta$ ) detection) and exposed to the respective primary antibody for $1 \mathrm{~h}$ at RT (insulin receptor $\beta$ subunit (IR $\beta$; Santa Cruz Biotechnology Inc, Santa Cruz, CA) and phosphoinositol-3-kinase (PI3K; Upstate Biotechnol-

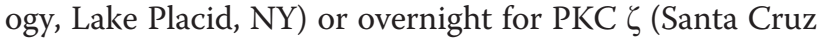
Biotechnology Inc). Specific antibodies were detected by secondary antibodies conjugated to horse radish peroxidase (1 h at RT; Sigma-Aldrich) and chemiluminescence was used for protein visualisation (Pierce). Specific protein expression was quantified densitometrically using Quantity One software (Bio-Rad). Intensity of signals between different blots was compared by using one or two reference samples on each blot.

\section{Statistical analyses}

For the statistical analyses of the of insulin signalling parameters a One-Way Analysis of Variance (effect of diet within lines) was used $\left(\mathrm{SAS}^{\odot}\right.$ Systems, Release 8.2, SAS Institute Inc., Cary, NC (SAS)). Protein expression was determined for each mice line separately comparing the different feeding groups. Statistical analysis for all the other traits was performed using the least-squares method and the GLM procedures of SAS. The following model was employed for the analysis of variance with the fix factors feeding (D) and selection (S): $Y_{i j k}=\mu+D_{i}+$ $\mathrm{P}_{\mathrm{j}}+\mathrm{D}_{\mathrm{i}} \times \mathrm{S}_{\mathrm{j}}+\mathrm{E}_{\mathrm{ijk}}$ (with $\mu=$ overall mean; $\mathrm{D}_{\mathrm{i}}=$ diet effect $(i=3) ; S_{j}=$ effect of selection $(j=2) ; D_{i} \times P_{j}=$ Interaction between diet and selection; $\mathrm{E}_{\mathrm{ijk}}=$ residual error). For the following variables, plasma leptin, C18:2n-6, C20:5n-3, $C 22: 5 n-3, C 22: 6 n-3$ and the ratio $n-6 / n-3$ in liver and C18:3n-3, C20:5n-3 and the ratio of $n-6 / n-3$ in muscle with different variances in diet groups, the SAS proc mixed program was used to model these different variances (by repeated statement and option group = diet). All Tables and Figure 1 contain the least squares mean (LSM) and the standard error (SE). All statistical tests (Tukey-Kramer) of LSM were performed for a significance level of $\mathrm{p} \leq 0.05$.

\section{Results}

The daily food intake was significantly different in the selection lines and clearly influenced by the different diets. Based on the long-term selection process described above, the DU6 mice showed a rapid growth trajectory during early postnatal life (overall difference in daily weight gain DU6 versus DUhTP, factor genetic line $\mathrm{p}<$ 0.0001 , factor diet $\mathrm{p}<0.001$, interaction $\mathrm{p}<0.01$; (mean daily weight gain in g/d DU6-standard chow 1.04 \pm 0.03 , n-3 HFD $1.21 \pm 0.02$, n-6 HFD $1.23 \pm 0.02$ (standard chow versus HFD p < 0.001) DUhTP-standard chow $0.34 \pm 0.01, \mathrm{n}-3$ HFD $0.40 \pm 0.02, \mathrm{n}-6$ HFD $0.37 \pm 0.01$ (standard chow versus n-3 HFD p < 0.05)) and were much heavier throughout the study (Table 2). Consequently, the DU6 mice consumed twice the amount of food than the DUhTP mice (Table 2). Feeding the HFD diets led to a decrease in the total amount of food (in grams) consumed in both mice lines compared to standard chow feeding. However, the relative amounts of food consumed, adjusted for the metabolic body weight $\left(\right.$ bwt $^{0.75}$ ) of the animals, was comparable between the DU6 and DUhTP mice, there was no effect of selection line. The daily calorie intake relative to bwt ${ }^{0.75}$ further revealed that all groups consumed very similar quantities of energy with only slightly higher calorie intake in the DUhTP mice fed the n-3 HFD (Table 2).

\section{Lipid metabolism}

Body fat deposition was influenced by selection line and by the specific diet. The DU6 mice deposited significantly more abdominal, perirenal and brown fat compared to DUhTP animals (Table 2). Consequently, the body weight at day 87 (end of the experiment) of DU6 mice was significant higher than the body weight of DUhTP mice in all feeding groups. Within the groups of DU6 mice, feeding either of the HFD resulted in a further increase in the weight of abdominal, perirenal and brown adipose tissues (Table 2). In contrast, feeding a HFD to DUhTP mice did not result in significant changes in fat deposition with abdominal adipose tissue weight reaching a small trend towards increased levels $(\mathrm{p}=0.06)$ in the $\mathrm{n}$ 3 HFD-fed animals compared to the standard chow-fed group (Table 2). Plasma leptin was measured as a blood marker of total adiposity. The larger adipose tissue mass in DU6 mice was reflected in leptin levels which were much higher in DU6 animals than in DUhTP animals (Table 3). Both HFD diets further increased plasma leptin concentrations in the DU6 mice compared to DU6 fed standard chow. The n-6 HFD had no effect on plasma leptin concentration in DUhTP animals while n-3 HFD increased plasma leptin concentrations slightly. Plasma FFA levels were higher in DU6 mice but unaffected by the HFD diets while total cholesterol was comparable in both selection lines. However, n-3 HFD decreased the cholesterol level significantly in DUhTP mice compared to the chow diet and the n-6 HFD groups (Table 3). Fat deposition in liver and muscle was not influenced by selection line or by feeding HFD except in n-6 HFD-fed DU6 mice, showing an increase in hepatic fat content (Table 2). However, n-3 HFD increased liver weight in both, DU6 and DUhTP (Table 2).

\section{Glucose metabolism}

Plasma glucose levels were similar in DU6 and DUhTP mice fed with standard chow. However, in DU6 mice both HFD diets increased glucose concentrations significantly. This was accompanied by an increase in plasma insulin but only in the DU6 mice fed on n-6 HFD. Insulin levels of DUhTP mice were generally lower and not influenced 
A. DU6 Hepatic IR $\beta$

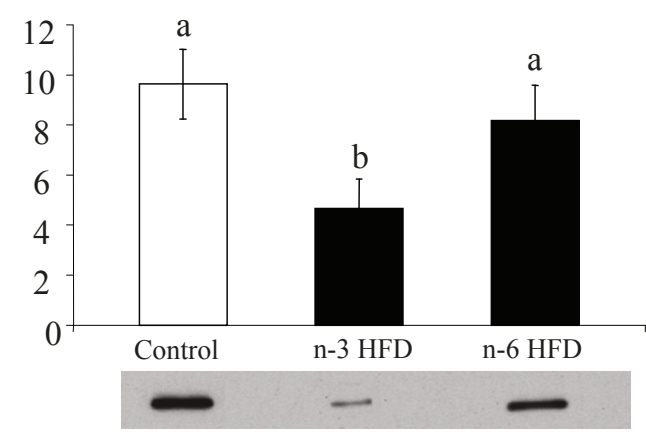

C. DU6 Hepatic PKC $\zeta$

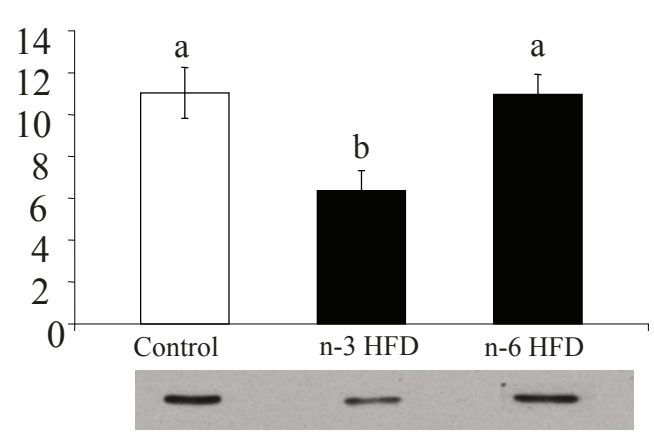

E. DU6 Adipose tissue PKC $\zeta$

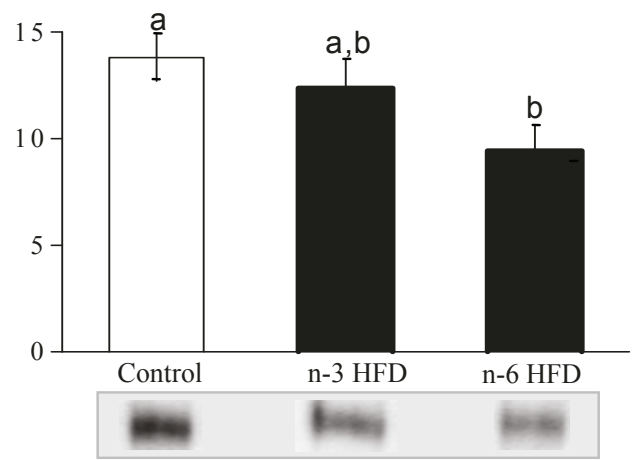

B. DUhTP Hepatic IR $\beta$

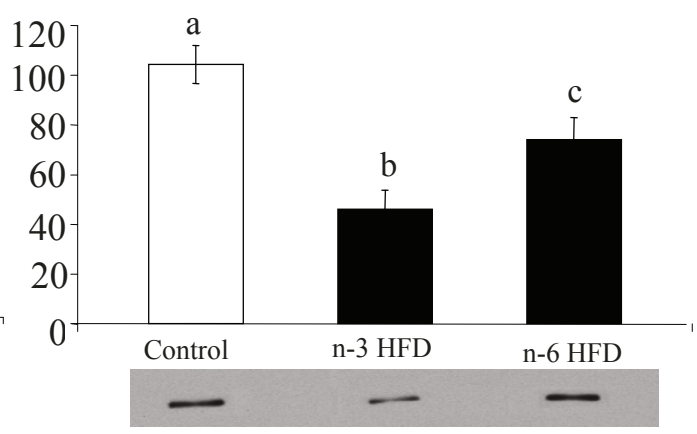

D. DUhTP Hepatic PKC $\zeta$

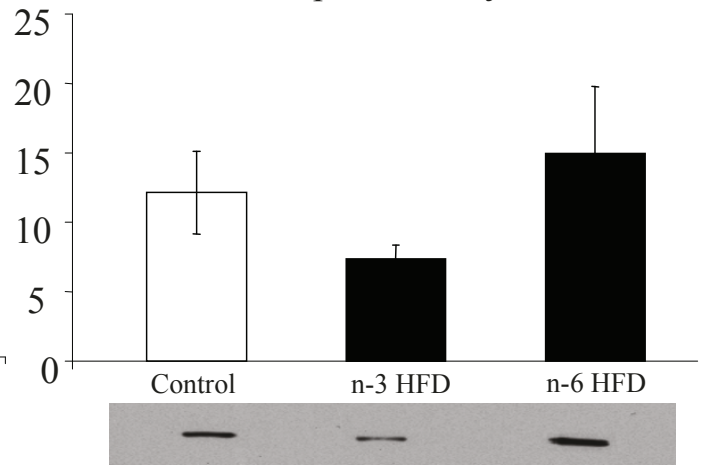

F. DUhTP Adipose tissue PKC $\zeta$

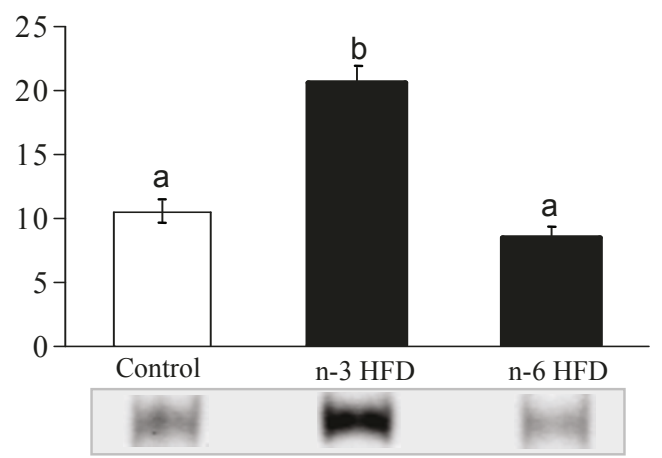

Figure 1 Effects of $n-3$ and $n-6$ high-fat diets on expression of insulin receptor $\beta$ protein in liver $(A, B)$ and protein kinase $C \zeta$ protein in liver $(C, D)$ and abdominal adipose tissue $(E, F)$ in mice with distinct biologically traits, of an "energy storage phenotype", the DU6 mice (high body weight line (, , C, E) and an "energy usage phenotype", the DUhTP mice (high treadmill performance line) (B, D, F). Trace quantity data are means $\pm \mathrm{SE}, \mathrm{n}=10$ /group; lower case letter mark significant differences $p<0.05$.

by HFD diets (Table 3). Expression of key proteins of insulin signalling in liver and abdominal adipose tissue was clearly influenced by HFD diets, but the effects differed in both selection lines. Hepatic IR $\beta$ expression was reduced in both, the DU6 and DUhTP animals fed on n-3 HFD. Furthermore, hepatic IR $\beta$ expression was also reduced in DUhTP animals fed on $n-6$ HFD but this reduction was less pronounced than in DUhTP mice fed on n-3 HFD (Figure 1). Hepatic p58 subunit of PI3K was increased only in DU6 mice fed on n-6 HFD compared to DU6 fed on $\mathrm{n}-3$ HFD $(160.3 \pm 17.1$ versus $90.5 \pm 19.7$, p < 0.001). Hepatic PKC $\zeta$ was significantly reduced only in DU6 mice fed on n-3 HFD while adipose tissue PKC $\zeta$ was reduced in DU6 mice fed on n-6 HFD. In DUhTP mice fed n-3 HFD a dramatic increase of PKC $\zeta$ protein expression was observed in adipose tissue while the n-6 HFD had no effect (Figure 1). In muscle ( $M$. quadriceps femoris), high-fat feeding did not influence expression 
Table 2 Effect of diet on body composition, daily food and energy intake of different mice lines

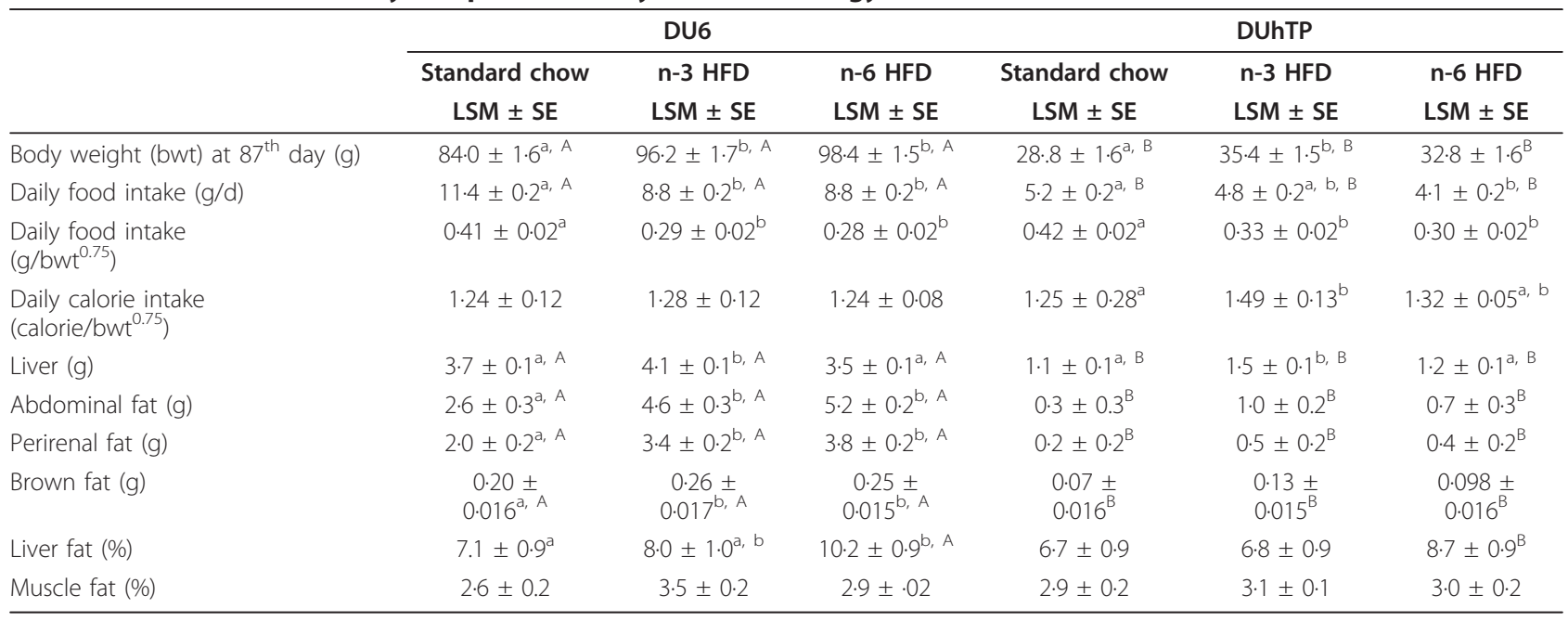

DU6-mouse line selected for high body weight; DUhTP-mouse line selected for high treadmill performance

$\mathrm{n}-3$ and $\mathrm{n}-6$ HFD-high fat diet enriched with either $n-3$ or $n-6$ polyunsaturated fatty acids

LSM-Least square means of 8-10 mice per group, SE-Standard error, bwt-body weight, bwt ${ }^{0.75}$ - metabolic body weight

$a$, b-significant effect of diet at $p \leq 0.05$ within the selected line

A, B -significant effect of selection line at $p \leq 0.05$ within the feeding group.

levels of IR $\beta$, PI3-kinase and PKC $\zeta$ in both selected lines (data not shown).

\section{Lipids in liver}

Analyses of liver lipids are shown in table 4. Differences based on selection line were mainly observed in mice fed n-6 HFD; there were fewer selection line effects with the standard chow diet and no selection line effects with n-3 HFD feeding. DU6 mice fed n-6 HFD synthesised significantly more palmitic acid (C16:0) and less stearic acid (C18:0) and arachidonic acid (C20:4n-6; AA) compared to DUhTP mice. Furthermore, DU6 mice fed n-6 HFD or standard chow accumulated more oleic acid (C18:1cis-9). As expected, n-3 HFD feeding of both selection lines massively increased the amount of eicosapentaenoic acid (C20:5n-3; EPA), docosapentaenoic acid
(C22:5n-3; DPA) and docosahexaenoic acid (C22:6n-3; DHA) and resulted in a lower deposition of AA.

Comparable to observations in muscle tissue, there were high amounts of myristic acid (C14:0) in liver of both mice lines when fed n-3 HFD. Concentration of oleic acid was lowest in DU6 mice fed n-3 HFD. Correspondingly, the calculated $\Delta^{9}$ desaturase (SCD) index was low in DU6 mice fed n-3 HFD compared to standard chow and n-6 HFD fed mice. Interestingly, in DUhTP mice fed standard chow, the SCD index was lower compared to that in DU6 mice, indicating a difference determined by selection. However, the SCD index was similar when DUhTP mice were fed $n-3$ and $n-6$ HFD, respectively. Accumulation of linoleic acid (C18:2n-6; LA) and AA was highest in the liver of $n-6$ HFD-fed mice of both selection lines. Feeding n-6 HFD

Table 3 Effect of diet on blood parameter of different mice lines

\begin{tabular}{|c|c|c|c|c|c|c|}
\hline & \multicolumn{3}{|c|}{ DU6 } & \multicolumn{3}{|c|}{ DUhTP } \\
\hline & Standard chow & n-3 HFD & n-6 HFD & Standard chow & n-3 HFD & n-6 HFD \\
\hline & $\mathrm{LSM} \pm \mathrm{SE}$ & $\mathrm{LSM} \pm \mathrm{SE}$ & $\mathrm{LSM} \pm \mathrm{SE}$ & $\mathrm{LSM} \pm \mathrm{SE}$ & $\mathrm{LSM} \pm \mathrm{SE}$ & $\mathrm{LSM} \pm \mathrm{SE}$ \\
\hline Leptin (ng/ml) & $9.8 \pm 3.1^{\text {a, A }}$ & $27 \cdot 9 \pm 2 \cdot 6^{\mathrm{b}, \mathrm{A}}$ & $27 \cdot 2 \pm 5 \cdot 5^{\mathrm{b}, \mathrm{A}}$ & $0 \cdot 8 \pm 0.3^{a, B}$ & $2.5 \pm 0.6^{\mathrm{b}, \mathrm{B}}$ & $1 \cdot 1 \pm 0.4^{a, b}, B$ \\
\hline Cholesterol (mM) & $4.7 \pm 0.8$ & $3.5 \pm 0.9$ & $5 \cdot 2 \pm 0.8$ & $6 \cdot 4 \pm 0.9^{a}$ & $4.0 \pm 0.8^{b}$ & $6 \cdot 5 \pm 0.8^{a}$ \\
\hline FFA (mM) & $1 \cdot 2 \pm 0.1^{\mathrm{A}}$ & $1 \cdot 2 \pm 0.1^{\mathrm{A}}$ & $1.4 \pm 0.1^{\mathrm{A}}$ & $0.8 \pm 0.1^{B}$ & $0.5 \pm 0.1^{B}$ & $0.8 \pm 0.1^{B}$ \\
\hline Insulin (ng/ml) & $1 \cdot 38 \pm 0.3^{a, b}, A$ & $0.98 \pm 0.3^{\mathrm{a}}$ & $1.81 \pm 0.3^{\mathrm{b}, \mathrm{A}}$ & $0.23 \pm 0.3^{B}$ & $0.21 \pm 0.3$ & $0 \cdot 19 \pm 0.3^{B}$ \\
\hline Glucose (mM) & $8.9 \pm 0.8^{a}$ & $11.0 \pm 0.8^{b, A}$ & $11 \cdot 2 \pm 0.8^{\mathrm{b}, \mathrm{A}}$ & $8.9 \pm 0.8$ & $8.9 \pm 0.8^{B}$ & $7.9 \pm 0.8^{B}$ \\
\hline
\end{tabular}

DU6-mouse line selected for high body weight; DUhTP-mouse line selected for high treadmill performance

$\mathrm{n}-3$ and $\mathrm{n}-6$ HFD-high fat diet enriched with either $n-3$ or $n-6$ polyunsaturated fatty acids

LSM-Least square means of 7-10 mice per group, SE-Standard error; FFA-free fatty acids;

$a$, b-significant effect of diet at $p \leq 0.05$ within the selected line

A, B-significant effect of selection line at $p \leq 0.05$ within the feeding group. 
Table 4 Effect of diet on fatty acid composition of liver of different mice lines

\begin{tabular}{|c|c|c|c|c|c|c|}
\hline & \multicolumn{3}{|c|}{ DU6 } & \multicolumn{3}{|c|}{ DUhTP } \\
\hline & Standard chow & n-3 HFD & n-6 HFD & Standard chow & n-3 HFD & n-6 HFD \\
\hline & $\mathrm{LSM} \pm \mathrm{SE}$ & $\mathrm{LSM} \pm \mathrm{SE}$ & $\mathrm{LSM} \pm \mathrm{SE}$ & $\mathrm{LSM} \pm \mathrm{SE}$ & $\mathrm{LSM} \pm \mathrm{SE}$ & $\mathrm{LSM} \pm \mathrm{SE}$ \\
\hline $\mathrm{SFA}^{+}$ & $2420 \pm 222$ & $2794 \pm 251$ & $2981 \pm 210$ & $1889 \pm 222$ & $2520 \pm 210$ & $2224 \pm 222$ \\
\hline C14:0 & $23 \cdot 2 \pm 8^{a}$ & $73 \cdot 1 \pm 9^{b}$ & $41 \cdot 2 \pm 7^{a, b}$ & $20 \cdot 0 \pm 8^{a}$ & $77.7 \pm 7^{b}$ & $23.4 \pm 8^{a}$ \\
\hline C16:0 & $1888 \pm 186$ & $2057 \pm 211$ & $2292 \pm 177^{A}$ & $1335 \pm 186$ & $1721 \pm 177$ & $1351 \pm 186^{\mathrm{B}}$ \\
\hline C18:0 & $435 \cdot 3 \pm 33$ & $560 \cdot 1 \pm 38$ & $547.5 \pm 32^{\mathrm{A}}$ & $436 \cdot 3 \pm 33^{a}$ & $589 \cdot 5 \pm 32^{b}$ & $733 \cdot 6 \pm 33^{c, B}$ \\
\hline MUFA" & $2074 \pm 225^{A}$ & $1567 \pm 256$ & $2544 \pm 214^{A}$ & $1006 \pm 225^{B}$ & $1473 \pm 214$ & $1547 \pm 226^{B}$ \\
\hline C16:1cis-9 & $218 \cdot 4 \pm 26$ & $247 \cdot 8 \pm 29$ & $143 \cdot 5 \pm 24$ & $110 \cdot 1 \pm 26^{a}$ & $244 \cdot 6 \pm 24^{b}$ & $89.9 \pm 25^{a}$ \\
\hline C18:1cis-9 & $1636 \pm 184^{a, b, A}$ & $1178 \pm 209^{a}$ & $2225 \pm 175^{\mathrm{b}, \mathrm{A}}$ & $793 \pm 185^{B}$ & $1044 \pm 175$ & $1355 \pm 185^{B}$ \\
\hline$\sum n-6 F A^{d}$ & $2706 \pm 438^{\mathrm{a}}$ & $754 \cdot 6 \pm 497^{b}$ & $6135 \pm 416^{c}$ & $2283 \pm 438^{a}$ & $759 \cdot 7 \pm 416^{b}$ & $5876 \pm 438^{a}$ \\
\hline$C 18: 2 n-6$ & $1941 \pm 269^{a}$ & $474 \cdot 8 \pm 47^{b}$ & $5003 \pm 575^{c}$ & $1686 \pm 349^{a}$ & $478 \pm 39^{b}$ & $4605 \pm 587^{c}$ \\
\hline$C 20: 4 n-6$ & $557.7 \pm 38^{a}$ & $226 \cdot 8 \pm 43^{b}$ & $727 \cdot 2 \pm 37^{\mathrm{CA}}$ & $479 \cdot 3 \pm 39^{a}$ & $236 \cdot 9 \pm 37^{b}$ & $902 \cdot 9 \pm 39^{c B}$ \\
\hline$\sum n-3 F A^{e}$ & $505 \cdot 0 \pm 144^{a}$ & $2385 \pm 163^{b}$ & $237.9 \pm 136^{a}$ & $556.6 \pm 144^{\mathrm{a}}$ & $2197 \pm 136^{b}$ & $110 \cdot 1 \pm 144^{a}$ \\
\hline C18:3n-3 & $70 \cdot 4 \pm 11^{a}$ & $93 \cdot 3 \pm 13^{a}$ & $13 \cdot 3 \pm 11^{b}$ & $63 \cdot 2 \pm 11^{a}$ & $85 \cdot 1 \pm 11^{a}$ & $8 \cdot 4 \pm 2^{b}$ \\
\hline$C 20: 5 n-3$ & $15 \cdot 6 \pm 3^{a}$ & $476 \cdot 6 \pm 64^{b}$ & $10 \cdot 0 \pm 4^{a}$ & $13 \cdot 2 \pm 3^{a}$ & $400 \cdot 9 \pm 53^{b}$ & $3 \cdot 7 \pm 4^{a}$ \\
\hline$C 22: 5 n-3$ & $22 \cdot 2 \pm 4^{a}$ & $133 \cdot 8 \pm 20^{b}$ & $11 \cdot 3 \pm 5^{a}$ & $33 \cdot 0 \pm 4^{a}$ & $114 \cdot 0 \pm 17^{b}$ & $20 \cdot 1 \pm 6^{a}$ \\
\hline$C 22: 6 n-3$ & $387 \cdot 6 \pm 19^{a}$ & $1634 \pm 180^{b}$ & $191 \cdot 3 \pm 32^{\mathrm{a}}$ & $439 \cdot 3 \pm 19^{a}$ & $1556 \pm 150^{b}$ & $73 \cdot 4 \pm 34^{a}$ \\
\hline PUFA & $3219 \pm 476^{a}$ & $3144 \pm 539^{a}$ & $6404 \pm 451^{b}$ & $2844 \pm 476^{a}$ & $2962 \pm 451^{a}$ & $5999 \pm 476^{b}$ \\
\hline$\Delta 9$ Desaturase index ${ }^{f}$ & $58 \cdot 8 \pm 2^{a, A}$ & $34 \cdot 4 \pm 3^{b}$ & $44 \cdot 5 \pm 2^{c}$ & $27 \cdot 0 \pm 2^{\mathrm{a}, \mathrm{B}}$ & $34 \cdot 2 \pm 2^{a, b}$ & $39 \cdot 3 \pm 2^{b}$ \\
\hline$n-6 / n-3$ ratio & $5 \cdot 3 \pm 0 \cdot 3^{a}$ & $0.3 \pm 0.02^{b}$ & $37 \cdot 6 \pm 6^{c_{1} A}$ & $4 \cdot 0 \pm 0.3^{\mathrm{a}}$ & $0.4 \pm 0.02^{b}$ & $52 \cdot 3 \pm 6^{c, B}$ \\
\hline
\end{tabular}

DU6-mouse line selected for high body weight; DUhTP-mouse line selected for high treadmill performance n-3 and n-6 HFD -high fat diet enriched with either $n$ 3 or $n-6$ polyunsaturated fatty acids

LSM-Least square means, SE-standard error, fatty acid concentrations in mg/100 $\mathrm{g}$ fresh tissue;

MUFA-monounsaturated fatty acids; SFA-saturated fatty acids; PUFA-polyunsaturated fatty acids; FA-fatty acids;

$a, b, c$-significant effect of diet at $p \leq 0.05$ within the selected line

A, B-significant effect of selection line at $\mathrm{p} \leq 0.05$ within the feeding group

+ Sum of saturated fatty acids $(C 10: 0+C 11: 0+C 12: 0+C 13: 0+C 14: 0+C 15: 0+C 16: 0+C 17: 0+C 18: 0+C 20: 0+C 21: 0+C 22: 0+C 23: 0+C 24: 0)$

\# Sum of MUFA (C14:1+C16:1+C17:1+ $\sum$ C18:1 trans isomers+C18:1 cis-9+C18:1 cis-11+C22:1+C24:1)

${ }^{d}$ Sum of $n-6$ fatty acids (C18:3n-6+C22:4n-6+C20:3n-6+C18:2n-6+C20:4n-6)

e Sum of $n-3$ fatty acids (C20:3n-3+C22:6n-3+C22:5n-3+C20:5n-3+C18:4n-3+C18:3n-3)

${ }^{f} \Delta 9$ Desaturase index $=((C 14: 1+C 16: 1+C 18: 1+C 17: 1) /(C 14: 1+C 16: 1+C 18: 1+C 17: 1+C 14: 0+C 16: 0+C 17: 0+C 18: 0))^{*} 100$.

increased the ratio of $n-6 / n-3$ fatty acids in the liver fat of both selection lines, and this effect was strongest in DUhTP mice.

\section{Lipids in quadriceps femoris muscle}

The lipid concentrations of muscle tissue are presented in table 5 . The fatty acid composition of skeletal muscle showed clear differences across the selection lines, but these patterns were distinct to those found in liver. Intriguingly, the DUhTP mice fed standard chow showed higher levels of DPA and DHA deposition in muscle compared to the DU6 animals. Concentrations of saturated fatty acids (SFA), monounsaturated fatty acids (MUFA), $\alpha$-linolenic acid (C18:3n-3; ALA) and EPA were increased in muscle of DU6 mice compared to DUhTP mice when fed n-3 HFD. The DU6 mice showed higher concentrations of LA and AA when fed n-6 HFD resulting in a comparable $n-6 / n-3$ ratio in both selection lines. The DU6 mice showed an increase in all SFA in muscle tissue in response to n-3 HFD compared to n-6 HFD and standard chow. This was not observed in DUhTP with the exception of the significant increase of myristic acid in both mice lines. Other responses to n-3 and n-6 HFD were quite similar between both selected lines. A summary of the responses to the HFD in both selection lines is presented in table 6 .

\section{Discussion}

The world-wide epidemic of obesity is due to complex, multifactorial changes in lifestyle and environmental conditions. In addition to an excess of calorie intake and composition of the diet, genetically determined pathways of energy storage and utilisation contribute to the development of obesity. The role of genetic factors in the pathogenesis of obesity is undeniable with familial clusters giving individuals in our modern "obesogenic" environment markedly different risks of becoming obese [21,22]. The present study investigates the fatty acid composition of tissues and the metabolic responses to high-fat diets rich in either $n-3$ or $n-6$ PUFA in mice, selected for high 
Table 5 Effect of diet on fatty acid composition of quadriceps femoris muscle of different mice line

\begin{tabular}{|c|c|c|c|c|c|c|}
\hline & \multicolumn{3}{|c|}{ DU6 } & \multicolumn{3}{|c|}{ DUhTP } \\
\hline & Standard chow & n-3 HFD & n-6 HFD & Standard chow & n-3 HFD & n-6 HFD \\
\hline & $\mathrm{LSM} \pm \mathrm{SE}$ & $\mathrm{LSM} \pm \mathrm{SE}$ & $\mathrm{LSM} \pm \mathrm{SE}$ & $\mathrm{LSM} \pm \mathrm{SE}$ & $\mathrm{LSM} \pm \mathrm{SE}$ & $\mathrm{LSM} \pm \mathrm{SE}$ \\
\hline$\overline{\mathrm{SFA}^{+}}$ & $365.5 \pm 45^{a}$ & $697 \cdot 2 \pm 48^{\mathrm{b}, \mathrm{A}}$ & $376 \cdot 6 \pm 43^{a}$ & $327 \cdot 0 \pm 45$ & $325 \cdot 1 \pm 43^{B}$ & $218 \cdot 2 \pm 45$ \\
\hline C14:0 & $11 \cdot 21 \pm 4^{a}$ & $62 \cdot 31 \pm 4^{\mathrm{b}, \mathrm{A}}$ & $9.58 \pm 4^{a}$ & $6 \cdot 5 \pm 4^{a}$ & $24 \cdot 1 \pm 4^{\mathrm{b}, \mathrm{B}}$ & $3.9 \pm 4^{a}$ \\
\hline C16:0 & $265 \cdot 9 \pm 34^{a}$ & $488.5 \pm 36^{\mathrm{b}, \mathrm{A}}$ & $248 \cdot 4 \pm 32^{\mathrm{a}}$ & $199 \cdot 3 \pm 34$ & $210 \cdot 0 \pm 32^{B}$ & $120 \cdot 2 \pm 34$ \\
\hline C18:0 & $62 \cdot 4 \pm 6^{a}$ & $98 \cdot 4 \pm 6^{\mathrm{bA}}$ & $91 \cdot 2 \pm 6^{a, b}$ & $85 \cdot 2 \pm 6^{a}$ & $57.7 \pm 6^{\mathrm{b} \mathrm{B}}$ & $68 \cdot 9 \pm 6^{a, b}$ \\
\hline MUFA $^{\#}$ & $225 \cdot 6 \pm 50^{\mathrm{a}}$ & $568 \cdot 2 \pm 53^{\mathrm{b}, \mathrm{A}}$ & $375.7 \pm 47$ & $180 \cdot 0 \pm 50$ & $280 \cdot 7 \pm 47^{B}$ & $183 \cdot 1 \pm 50$ \\
\hline C16:1 cis-9 & $70 \cdot 4 \pm 10^{a, b}, A$ & $96 \cdot 6 \pm 10^{a_{1}} \mathrm{~A}$ & $36 \cdot 7 \pm 9^{b}$ & $25 \cdot 4 \pm 10^{B}$ & $41.6 \pm 9^{B}$ & $14 \cdot 1 \pm 10$ \\
\hline C18:1 cis-9 & $206 \cdot 7 \pm 33$ & $320.8 \pm 35^{\mathrm{A}}$ & $296 \cdot 4 \pm 31^{A}$ & $116 \cdot 8 \pm 33$ & $149.5 \pm 31^{B}$ & $145.8 \pm 33^{B}$ \\
\hline$\sum n-6 F A^{d}$ & $345 \cdot 0 \pm 44^{\mathrm{a}}$ & $141 \cdot 6 \pm 47^{b}$ & $800 \cdot 6 \pm 42^{\mathrm{CA}}$ & $302 \cdot 5 \pm 44^{a}$ & $70 \cdot 6 \pm 42^{b}$ & $445 \cdot 0 \pm 44^{\mathrm{a}, \mathrm{B}}$ \\
\hline C18:2n-6 & $225 \cdot 6 \pm 42^{a}$ & $100 \cdot 9 \pm 44^{\mathrm{a}}$ & $653.3 \pm 40^{\mathrm{b} A}$ & $167 \cdot 5 \pm 42^{\mathrm{a}, \mathrm{B}}$ & $43 \cdot 2 \pm 40^{\mathrm{a}}$ & $318.7 \pm 42^{\mathrm{bB}}$ \\
\hline$C 20: 4 n-6$ & $98 \cdot 2 \pm 5^{a}$ & $25 \cdot 4 \pm 5^{b}$ & $112 \cdot 7 \pm 5^{a_{1} A}$ & $108.4 \pm 5^{a}$ & $20 \cdot 4 \pm 5^{b}$ & $91 \cdot 2 \pm 5^{\mathrm{aB}}$ \\
\hline$\sum n-3 F A^{e}$ & $99 \cdot 5 \pm 12^{\mathrm{a}, \mathrm{A}}$ & $325.0 \pm 13^{b, A}$ & $37.9 \pm 12^{c}$ & $171 \cdot 8 \pm 12^{\mathrm{a}, \mathrm{B}}$ & $270 \cdot 6 \pm 12^{\mathrm{b}, \mathrm{B}}$ & $25 \cdot 7 \pm 12^{c}$ \\
\hline C18:3n-3 & $9 \cdot 4 \pm 1.6^{a}$ & $48 \cdot 0 \pm 5^{\mathrm{b}, A}$ & $2 \cdot 3 \pm 0 \cdot 3^{a}$ & $5.7 \pm 1.6$ & $6 \cdot 8 \pm 5^{B}$ & $1.3 \pm 0.4$ \\
\hline$C 20: 5 n-3$ & $0.9 \pm 0.1^{a}$ & $50 \cdot 5 \pm 0.5^{\mathrm{b}, \mathrm{A}}$ & $1 \cdot 0 \pm 0 \cdot 2^{\mathrm{a}, \mathrm{A}}$ & $1 \cdot 3 \pm 0.1^{a}$ & $26 \cdot 4 \pm 4^{\mathrm{bB}}$ & $0.1 \pm 0.2^{c, B}$ \\
\hline$C 22: 5 n-3$ & $7.9 \pm 1^{\mathrm{a}, \mathrm{A}}$ & $23 \cdot 1 \pm 1^{b}$ & $3 \cdot 1 \pm 1^{a}$ & $22 \cdot 3 \pm 1^{\mathrm{a}, \mathrm{B}}$ & $20 \cdot 5 \pm 1^{a}$ & $2 \cdot 7 \pm 1^{b}$ \\
\hline$C 22: 6 n-3$ & $80 \cdot 6 \pm 9^{a, A}$ & $201 \cdot 2 \pm 9^{b}$ & $30 \cdot 7 \pm 8^{c}$ & $142 \cdot 1 \pm 8^{\mathrm{a}, \mathrm{B}}$ & $215 \cdot 6 \pm 8^{b}$ & $21 \cdot 3 \pm 9^{c}$ \\
\hline PUFA & $445 \cdot 2 \pm 50^{a}$ & $468 \cdot 8 \pm 53^{a}$ & $839.6 \pm 48^{\mathrm{b}, \mathrm{A}}$ & $475.0 \pm 50$ & $342 \cdot 0 \pm 47$ & $471 \cdot 7 \pm 50^{B}$ \\
\hline $\begin{array}{l}\triangle 9 \text { Desaturase } \\
\text { index }\end{array}$ & $43.4 \pm 2^{a, b}$ & $41 \cdot 2 \pm 2^{a}$ & $48 \cdot 5 \pm 2^{\mathrm{b}, \mathrm{A}}$ & $33 \cdot 7 \pm 2^{a}$ & $42 \cdot 5 \pm 2^{b}$ & $45 \cdot 0 \pm 2^{b, B}$ \\
\hline$n-6 / n-3$ ratio & $3.4 \pm 0.2^{\mathrm{a}, \mathrm{A}}$ & $0.40 \pm 0.02^{b, A}$ & $23 \cdot 8 \pm 2 \cdot 6^{c}$ & $1.9 \pm 0.2^{\mathrm{a}, \mathrm{B}}$ & $0.3 \pm 0.02^{\mathrm{b}, \mathrm{B}}$ & $17 \cdot 6 \pm 2 \cdot 8^{c}$ \\
\hline
\end{tabular}

DU6-mouse line selected for high body weight; DUhTP-mouse line selected for high treadmill performance

$\mathrm{n}-3$ and $\mathrm{n}-6 \mathrm{HFD}$-high fat diet enriched with either $n-3$ or $n-6$ polyunsaturated fatty acids

LSM-Least square means, SE-Standard error, fatty acid concentrations in $\mathrm{mg} / 100 \mathrm{~g}$ fresh tissue;

MUFA-monounsaturated fatty acids; SFA-saturated fatty acids; PUFA-polyunsaturated fatty acids; FA-fatty acids;

$a, b, c$-significant effect of diet at $p \leq 0.05$ within the selected line,

A, B -significant effect of selection line at $\mathrm{p} \leq 0.05$ within the feeding group; all interaction DxL were significant at $\mathrm{p} \leq 0.05$;

+ Sum of saturated fatty acids: $(\mathrm{C} 10: 0+\mathrm{C} 11: 0+\mathrm{C} 12: 0+\mathrm{C} 13: 0+\mathrm{C} 14: 0+\mathrm{C} 15: 0+\mathrm{C} 16: 0+\mathrm{C} 17: 0+\mathrm{C} 18: 0+\mathrm{C} 20: 0+\mathrm{C} 21: 0+\mathrm{C} 22: 0+\mathrm{C} 23: 0+\mathrm{C} 24: 0)$

\# Sum of MUFA (C14:1+C16:1+C17:1+ $\sum$ C18:1 trans isomers $+C 18: 1$ cis-9+C18:1cis-11+C22:1+C24:1)

${ }^{d}$ Sum of $n-6$ FA (C18:3n-6+ C22:4n-6+ C20:3n-6+C18:2n-6+C20:4n-6)

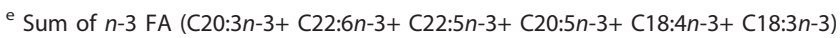

${ }^{\mathrm{f}} \Delta 9$ Desaturase index $=((\mathrm{C} 14: 1+\mathrm{C} 16: 1+\mathrm{C} 18: 1+\mathrm{C} 17: 1) /(\mathrm{C} 14: 1+\mathrm{C} 16: 1+\mathrm{C} 18: 1+\mathrm{C} 17: 1+\mathrm{C} 14: 0+\mathrm{C} 16: 0+\mathrm{C} 17: 0+\mathrm{C} 18: 0)) * 100$.

body weight (DU6), leading to rapid obesity development, or selected for high treadmill performance, leading to a lean phenotype. This study also investigates whether different metabolic responses may be linked to changes in insulin signalling pathways in liver, muscle and adipose tissue. The mouse lines used in the present study reflect the range of genetic predisposition to obesity development commonly observed under physiological conditions [26].

It is most likely that selection of these mouse lines produced metabolic phenotypes by polygenic variants of genes as described in human populations [33]. The mice lines used in this study reveal distinct metabolic phenotypes. The DU6 mice display an "energy storage phenotype" that is characterised by high body weight, increased food intake, larger fat depots, higher liver weight and higher plasma FFA, leptin and insulin levels. In contrast, the DUhTP mice display an "energy usage phenotype" that is characterised by lower body weight, less food intake, smaller fat depots, lower liver weight and lower plasma FFA, leptin and insulin levels. The findings of the present study also suggest that there is a strong genetic contribution to the pattern of fatty acid composition of body tissues. The selection lines showed clear differences in the fatty acid composition of liver and muscle even under standard chow feeding conditions. These data are supported by studies in pigs which showed a significant heritability of fatty acid composition in muscle, especially for the concentrations of $n-3$ and $n-6$ PUFA [34]. Interestingly, in liver, the amount of oleic acid was lower in DUhTP mice in comparison with DU6 mice which may be related to the reduced capacity to synthesise oleic acid from stearic acid as indicated by the decrease in delta- 9 desaturase index. In muscle, palmitoleic acid content was also lower in DUhTP. This difference in the SCD index between selection lines appears to have a genetic origin. Furthermore the capacity for the de novo synthesis of long-chain $n-3$ PUFA, DHA and DPA, in muscle was elevated in DUhTP mice fed standard chow compared to DU6 mice. This may lead to increased insulin sensitivity, an association which has been previously observed in human skeletal muscle 
Table 6 Summary of major effects of n-3 and n-6 HFD on lipid and glucose metabolism

\begin{tabular}{|c|c|c|c|c|c|c|c|c|c|}
\hline \multirow[b]{2}{*}{$\begin{array}{l}\text { Lipid } \\
\text { metabolism }\end{array}$} & \multicolumn{2}{|c|}{ DU6 } & \multicolumn{2}{|c|}{ DUhTP } & \multirow[b]{2}{*}{$\begin{array}{l}\text { Glucose } \\
\text { metabolism }\end{array}$} & \multicolumn{2}{|c|}{ DU6 } & \multicolumn{2}{|c|}{ DUhTP } \\
\hline & n-3 HFD & n-6 HFD & n-3 HFD & n-6 HFD & & n-3 HFD & n-6 HFD & n-3 HFD & n-6 HFD \\
\hline Leptin & $\uparrow$ & $\uparrow$ & $\uparrow$ & - & Insulin & - & $(\uparrow)$ & - & - \\
\hline FFA & - & - & - & - & Glucose & $\uparrow$ & $\uparrow$ & - & - \\
\hline Cholesterol & - & - & $\downarrow$ & - & Liver IR $\beta$ & $\downarrow$ & - & $\downarrow$ & $\downarrow$ \\
\hline Fat deposition & $\uparrow$ & $\uparrow$ & $(\uparrow)$ & - & Liver PI3K & - & - & - & - \\
\hline Body weight & $\uparrow$ & $\uparrow$ & $\uparrow$ & - & Liver PKC & $\downarrow$ & - & - & - \\
\hline Liver weight & $\uparrow$ & - & $\uparrow$ & - & Muscle IR $\beta$ & - & - & - & - \\
\hline \multirow[t]{3}{*}{ Liver fat } & - & $\uparrow$ & - & - & 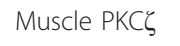 & - & - & - & - \\
\hline & & & & & Muscle PI3K & - & - & - & - \\
\hline & & & & & 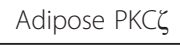 & - & $\downarrow$ & $\uparrow$ & - \\
\hline \multicolumn{5}{|c|}{$\begin{array}{l}\text { Fatty acid composition } \\
\text { liver }\end{array}$} & \multicolumn{3}{|c|}{$\begin{array}{l}\text { Fatty acid composition } \\
\text { muscle }\end{array}$} & & \\
\hline SFA & - & - & - & - & SFA & $\uparrow$ & - & - & - \\
\hline Myristic acid & $\uparrow$ & - & $\uparrow$ & - & Myristic acid & $\uparrow$ & - & $\uparrow$ & - \\
\hline Palmitic acid & - & - & - & - & Palmitic acid & $\uparrow$ & - & - & - \\
\hline Stearic acid & - & - & $\uparrow$ & $\uparrow$ & Stearic acid & $\uparrow$ & - & $\downarrow$ & - \\
\hline Oleic acid & - & $(\uparrow)$ & - & & Oleic acid & - & - & - & - \\
\hline MUFA & - & - & - & - & MUFA & $\uparrow$ & - & - & - \\
\hline PUFA & - & $\uparrow$ & - & $\uparrow$ & PUFA & - & $\uparrow$ & - & - \\
\hline n-3 PUFA & $\uparrow$ & - & $\uparrow$ & - & n-3 PUFA & $\uparrow$ & $\downarrow$ & $\uparrow$ & $\downarrow$ \\
\hline n-6 PUFA & $\downarrow$ & $\uparrow$ & $\downarrow$ & - & n-6 PUFA & $\downarrow$ & $\uparrow$ & $\downarrow$ & - \\
\hline
\end{tabular}

DU6-mouse line selected for high body weight; DUhTP-mouse line selected for high treadmill performance

n-3 and n-6 HFD-high fat diet enriched with either $n-3$ or $n-6$ polyunsaturated fatty acids

FFA-free fatty acids; IR $\beta$-Insulin receptor $\beta$ subunit; PI3K-phosphatidyl inositol-3 kinase; PKC $\zeta$-atypical protein kinase $\zeta$; PUFA-polyunsaturated fatty acids; MUFAmonounsaturated fatty acids

- no change; $\uparrow$ increase compared to respective standard chow fed group; $\downarrow$ decrease compared to respective standard chow group; ( $\downarrow$ )( $\uparrow)$ tendency to decrease/ increase.

containing increased proportions of PUFA with twenty and twenty-two carbons [35]. Increased $n$ - 3 PUFA content in muscle cells was identified as a key driver of inner mitochondrial membrane properties, thereby affecting membrane-associated proteins [36]. Carnitine palmitoyltransferase activity was increased by dietary $n-3$ PUFA suggesting an enhanced lipolytic capacity in skeletal muscle and enhanced mitochondrial membrane fluidity [37]. It is therefore tempting to speculate that the increased $n-3$ PUFA concentrations in muscle may contribute to a metabolic status in DUhTP that leads to the energy usage phenotype and to the ability to adapt more successfully to a HFD. In contrast, DU6 mice have significantly less longchain $n$-3 PUFA concentrations in muscle, they have lower insulin signalling capacity (unpublished results) and probably less oxidative capacity to burn fatty acids in skeletal muscle resulting in the energy storage phenotype.

\section{Different responses to $n-3$ HFD or n-6 HFD}

The mechanisms underlying diet-induced obesity are still not fully understood, but are influenced by a range of genetic factors [38]. The present study investigated metabolic responses to isocaloric high-fat diets enriched with either n-3 PUFA or $n$ - 6 PUFA in two long-term selected lines of mice. The metabolic responses of the animals were defined by measuring key markers of lipid and glucose metabolism in plasma, liver, muscle and adipose tissue and by determining fatty acid composition of liver and muscle. In agreement with many previous studies, fatty acid composition of body tissues was mainly determined by dietary fat intake in both lines of mice. [39,40]. However, the specific metabolic responses in body tissues to a HFD enriched with $n-3$ or $n-6$ PUFA differed markedly between the two selection lines. Major effects are discussed below, separately, for lipid and glucose metabolism. Different responses to HFD occurred despite similar calorie intake per bwt ${ }^{0.75}$ between the feeding groups and between the selection lines. Thus, our data suggest that mice with a predisposition for obesity development, the energy storage phenotype, or to leanness, the energy usage phenotype, respond differently to isocaloric HFD rich in $n-3$ PUFA or $n-6$ PUFA. However, the formulation of the diets used in the present study had two limitations. Firstly, differences in protein content of the control diet and the high-fat diets could have potentially influenced some metabolic processes. Secondly, the higher content of myristic acid in $n-3$ HFD may have modified some of the biological effects. Although unlikely, the magnitude 
of such potential influences could not be addressed in the present study.

\section{Lipid metabolism}

One of the most important contributing factors to obesity development is the increased consumption of energydense foods resulting in higher calorie intake and higher intake of dietary fat [41]. Interestingly, only the DU6 mice showed a significant increase in adipose tissue weight in response to both the n-3 HFD and the n-6 HFD. Body weight increased significantly in DU6 mice fed either n-3 or n-6 HFD due to the high calorie density of these diets, although food intake measured in grams was reduced. The higher body weight of DU6 mice was mainly due to increased fat deposition, emphasising the energy storage phenotype of these animals. The effects of the HFD on parameters of adiposity were almost missing in DUhTP mice. Interestingly, the increase in adiposity in DU6 mice was not caused by changes in food intake; the calorie intake per bwt ${ }^{0.75}$ was very similar between the different selection lines. These data clearly underscore the biological importance of genetically determined pathways of energy utilisation that contribute to the development of obesity.

Many dietary components and metabolic conditions are known to be involved in nutrient partitioning that shift energy from storage in adipose tissues to energy utilisation in muscle and to muscle protein synthesis [42-45]. A lower capacity to oxidise fat in skeletal muscle and liver in high fat feeding conditions was stipulated as the main driver of shifting energy into storage as fat in obesity-prone rats [44]. Data from the present study suggest that dietary $n-3$ and $n-6$ PUFA may play a role in nutrient partitioning. The DUhTP mice fed a HFD showed a remarkable adaptive response. Although body weight was increased in the n-3 HFD group, total cholesterol levels were decreased when DUhTP mice were fed n-3 HFD, indicating a health benefit on lipid metabolism of the $n-3$ PUFA diet by inhibiting cholesterol synthesis [46]. In addition, in DUhTP there was only a trend of an increase in adipose tissue weights and a slight, but significant increase in plasma leptin concentrations when fed n-3 HFD, conveying further health benefits on lipid metabolism. These intriguing findings warrant further study and may involve $n$ - 3 PUFAmediated changes in peripheral oxidation of fatty acids, especially in individuals with an energy usage phenotype $[37,47,48]$.

\section{Glucose metabolism}

The main differences in glucose metabolism responses to n-3 HFD and n-6 HFD for the two selection lines are described by the following main findings. Plasma glucose concentrations were increased by both HFD in DU6 mice. In addition, plasma insulin concentrations in DU6 fed n-6 HFD were increased suggesting development of insulin resistance [49]. In contrast, HFD-induced hyperglycaemia and hyperinsulinaemia was absent in DUhTP mice. Interestingly, in both selection lines n-3 HFD reduced hepatic protein expression of a key component of the insulin signalling pathway, the $\beta$-subunit of the IR $\beta$, while the PKC $\zeta$ signalling protein concentration was reduced in liver tissue of DU6 mice only. In contrast, in abdominal adipose tissue, the PKC $\zeta$ protein expression was strongly increased by n-3 HFD indicating a higher capacity for glucose uptake. Importantly, this effect was only observed in DUhTP mice. In previous studies it was suggested that the adipose tissue is a key player in modulating insulin-sensitising effects of dietary $n-3$ PUFA $[50,51]$. Although the underlying molecular pathways are still uncertain, our data suggest that up-regulation of PKC $\zeta$ within the insulin signalling cascade by dietary $n-3$ PUFA may explain the insulin-sensitising effects. The present study showed for the first time that PKC $\zeta$ may be a target of $n-3$ PUFA action in a tissue-specific manner. It is increasingly appreciated that the insulin-sensitising effects in adipocytes may be crucial for the health benefits of dietary $n-3$ PUFA [36].

Interestingly, PKC $\zeta$ expression was unchanged in adipose tissue when DU6 mice were fed n-3 HFD, but hepatic insulin signalling parameters decreased. Consequently, plasma glucose concentrations increased but without any changes in insulin concentration. It is intriguing that muscle tissue did not respond to the HFD in either of the selection lines suggesting that skeletal muscle may be less responsive to dietary regulating of insulin sensitivity in mice fed HFD. Comparable results were obtained in a study using C57BL/6J mice after an eight-week HFD showing only minor changes in muscular transcriptome [52]. The increase in PKC $\zeta$ expression in adipose tissue and the decrease in liver insulin signalling in DUhTP mice offers novel pathways for cellular mechanism of glucose partitioning in response to increased dietary $n-3$ PUFA. This shift in glucose re-partitioning may also be induced in DU6 mice fed n-3 HFD; however, any effect will be less efficient due to the lack of increased PKC $\zeta$ expression in adipose tissue. This notion is supported by our observation of increased plasma glucose concentrations with n-3 HFD in DU6 mice. HFD enriched with $n-6$ PUFA led to hyperglycaemia and hyperinsulinaemia in DU6 mice indicating insulin resistance which is commonly induced by HFD feeding [49]. The observed decrease in PKC $\zeta$ expression in adipose tissue may contribute to development of insulin resistance in the energy storage phenotype, again, demonstrating the important metabolic role of adipose tissue in the regulation of insulin sensitivity. In contrast, DUhTP mice showed only small shifts in hepatic insulin signalling when fed with $n-6$ HFD which was paralleled by 
plasma glucose and insulin concentrations within the normal physiological range. The data suggest that the capacity to deposit glucose in insulin-sensitive adipose tissue and liver was maintained in the energy usage phenotype even in the face of a n-6 HFD.

\section{Fatty acid composition}

The n-3 and n-6 HFD resulted in different fatty acid composition of liver and muscle in DU6 and DUhTP mice. These changes in fatty acid composition reflect the fatty acid composition of the diet which has been demonstrated previously in studies by Valencak and Ruf [19] and Poureslami et al. [53]. Diet-induced changes were observed in the content of myristic acid which is increased in both, muscle and liver of each line fed n-3 HFD reflecting the high myristic acid content of this diet. Similarly, the increase in $n$-3 PUFA concentrations with a simultaneous decrease of $n-6$ PUFA concentrations in muscle and liver with n-3 HFD feeding was observed in both lines of mice indicating a dominant influence of the dietary fat content. However, some differences seemed to be set by long-term selection of the mice lines indicating a high heritability of fatty acid composition in some tissues. The heritability of body tissues fatty acid composition, especially the deposition of $n-3$ PUFA, has been widely studied in many species, including pigs, salmon and humans $[34,54,55]$. In DUhTP mice deposition of ALA and EPA was lower in muscle resulting in a smaller sum of $n$-3 PUFA when the n-3 HFD was fed. The lower content of $n-3$ PUFA in muscle, most likely located in cell and mitochondrial membranes, suggests a lower susceptibility to peroxidation compared to DU6 [56], thereby contributing to muscle cell viability and performance in DUhTP. It is tempting to speculate that an increase in the antioxidant capacity in DUhTP mice may also lower susceptibility to peroxidation, thus providing further health benefits of dietary $n-3$ PUFA [57]. This may contribute to the increased running performance in DUhTP mice and support the energy usage phenotype. An increase in the n-6 PUFA content of body tissues was expected with n6 HFD feeding, however, this was only observed in DU6 liver and muscle and not in the DUhTP animals indicating again a genetic component of fatty acid deposition. Another remarkable difference in specific fatty acid deposition in muscle was observed regarding the SFA content, especially palmitic and stearic acid. Feeding $n-3$ HFD increased the content of these SFA in DU6 but not in DUhTP mice. These results may suggest that lipogenic pathways are amplified in the DU6 line because palmitic acid is the end product of de novo fatty acid synthesis. Enhanced capacity for lipogenesis, even when HFD are fed, may contribute to the development of the energy storage phenotype of the DU6 mice.

\section{Summary}

Data presented in this paper advance our understanding about the interactions between genetic predisposition and environmental influences in the development of obesity and its metabolic complications. Mice from longterm selection experiments served as models to examine the contributions of genetic factors in determining specific dietary influences on metabolic regulation relevant to obesity development. Mice lines with distinct biological traits, of an "energy storage phenotype", the DU6 mice; and of an "energy usage phenotype", the DUhTP mice served to investigate whether different genetic predispositions for obesity or leanness may favour specific metabolic pathways and down-stream effects of lipid or carbohydrate metabolism. The specific metabolic responses in body tissues to a HFD enriched with $n-3$ or n-6 PUFA differed markedly between the two selection lines despite similar calorie intake per bwt ${ }^{0.75}$ between the selection lines. In DUhTP mice, the effects of the HFD on parameters of adiposity such as large fat pads, high plasma cholesterol, triglyceride, glucose and insulin concentrations were almost missing, drawing attention to the biological importance of genetically determined pathways that contribute to the development of obesity. The results of the present study also suggest that dietary $n-3$ PUFA may play an important role in nutrient partitioning. Metabolic health benefits of dietary $n$ - 3 PUFA may be explained, at least in part, by changes in insulin action and lipid metabolism through re-partitioning of energy from liver and muscle to adipose tissue. The present study showed for the first time that PKC $\zeta$ within the insulin signalling cascade may be a target of dietary $n-3$ PUFA action in a tissue-specific manner. The up-regulation of PKC $\zeta$ in adipose tissue may explain the insulinsensitising effects of dietary $n-3$ PUFA. However, important genotype-diet interactions may explain why such diets may have modest effects in some population groups.

\section{List of abbreviations}

DM: dry matter; HFD: high fat diet, IR $\beta$ : Insulin receptor $\beta$; PKC $\zeta$ : protein kinase $C \zeta_{\text {; }}$ PI3K: p85 subunit of the phosphatidyl inositol-3-phosphate kinase; EPA: eicosapentanenoic acid; DHA: docosahexaenoic acid; DPA: docosapentaenoic acid, PUFA: polyunsaturated fatty acids, SCD: $\Delta^{9}$ desaturase, FAS: fatty acid synthase, SREBP-1: sterol regulatory elementbinding protein 1, PPAR: peroxisome proliferator-activated receptor; LA: linoleic acid; AA: arachidonic acid; ALA-a: linolenic acid

\section{Acknowledgements}

The authors wish to thank Mrs. Jentz and Mrs. Dahm for the analytical measurements of lipid metabolism. This research was supported by the Federal Ministry of Food, Agriculture and Consumer Protection in Germany. $\mathrm{BHB}$ and NT were supported by the Health Research Council of New Zealand and the National Research Centre for Growth and Development.

\section{Author details}

${ }^{1}$ Leibniz Institute for Farm Animal Biology, Department of Muscle Biology and Growth, 18196 Dummerstorf, W.-Stahl-Allee 2, Germany. ${ }^{2}$ Institute of Food, Nutrition and Human Health, Massey University, Albany Campus, 
Private Bag 102 904, North Shore Mail Centre, Auckland, New Zealand. ${ }^{3}$ School of Biological Sciences, Faculty of Science, University of Auckland, Auckland, New Zealand. ${ }^{4}$ Department of Physiology, University of Veterinary Medicine Hannover, 30173 Hannover, Germany. ${ }^{5}$ Discipline of Physiology, School of Medical Sciences, The University of Adelaide, Adelaide, Australia. ${ }^{6}$ Leibniz Institute for Farm Animal Biology, Department of Genetic and Biometry, 18196 Dummerstorf, W.-Stahl-Allee 2, Germany. 'eibniz Institute for Farm Animal Biology, Department of Reproductive Biology, 18196 Dummerstorf, W.-Stahl-Allee 2, Germany.

\section{Authors' contributions}

$\mathrm{KN}, \mathrm{DD}, \mathrm{BHB}$ and $\mathrm{KH}$ participated in the formulation and design of the study. UR and ML participated in the selection breeding to produce the different mice lines, conducted the animal HFD feeding experiment and collected samples. SJ, NT and HB performed Western Blot analyses in liver, muscle (SJ) and adipose tissues (HB) including final analysis of data. KN, FS and DD performed the fatty acid and blood metabolite analyses. GN performed statistical analyses of the data. $\mathrm{BHB}, \mathrm{KN}$ and $\mathrm{KH}$ developed the manuscript in its final form. All authors read and approved the final manuscript.

\section{Competing interests}

The authors declare that they have no competing interests.

Received: 14 April 2011 Accepted: 11 August 2011

Published: 11 August 2011

\section{References}

1. Nguyen DM, El-Serag HB: The epidemiology of obesity. Gastroenterol Clin North Am 2010, 39(1):1-7.

2. World Health Organization: Obesity. 2008 [http://www.who.int/topics/ obesity/en/].

3. O'Rahilly S: Human genetics illuminates the paths to metabolic disease. Nature 2009, 462(7271):307-14.

4. Mann Jl: Nutrition recommendations for the treatment and prevention of type 2 diabetes and the metabolic syndrome: an evidenced-based review. Nutr Rev 2006, 64(9):422-7.

5. Deckelbaum RJ, Calder PC: Dietary n-3 and n-6 fatty acids: are there "bad" polyunsaturated fatty acids? Curr Opin Clin Nutr Metab Care 2010, 13:123-124.

6. Jump DB: $N-3$ polyunsaturated fatty acid regulation of hepatic gene transcription. Current Opinion in Lipidology 2008, 19:242-247.

7. Buettner R, Parhofer KG, Woenckhaus M, Wrede CE, Kunz-Schughart LA, Schölmerich J, Bollheimer LC: Defining high-fat diet rat models: metabolic and molecular effects of different fat types. $J$ Mol Endocrinol 2006, 36:485-501.

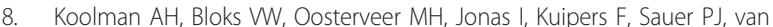
Dijk G: Metabolic responses to long-term pharmacological inhibition of CB1-receptor activity in mice in relation to dietary fat composition. Int J Obes (Lond) 2010, 34:374-382

9. Park SY, Cho YR, Kim HJ, Higashimori T, Danton C, Lee MK, Dey A, Rothermel B, Kim YB, Kalinowski A, Russell KS, Kim JK: Unraveling the temporal pattern of diet-induced insulin resistance in individual organs and cardiac dysfunction in C57BL/6 mice. Diabetes 2005, 54:3530-3540.

10. Frangioudakis G, Ye J-M, Cooney GL: Both saturated and $n-6$ polyunsaturated fat diets reduce phosphorylation of insulin receptor substrate- 1 and protein kinase B in muscle during the initial stages of in vivo insulin stimulation. Endocrinology 2005, 146:596-603.

11. Tremblay F, Lavigne C, Jacques $H$, Marette A: Defective insulin-induced GLUT4 translocation in skeletal muscle of high fat-fed rats is associated with alterations in both Akt/protein kinase B and atypical protein kinase C (zeta/lambda) activities. Diabetes 2001, 50:1901-10.

12. Turner N, Bruce CR, Beale SM, Hoehn KL, So T, Rolph MS, Cooney GJ: Excess lipid availability increases mitochondrial fatty acid oxidative capacity in muscle: evidence against a role for reduced fatty acid oxidation in lipidinduced insulin resistance in rodents. Diabetes 2007, 56:2085-92.

13. Perdomo G, Commerford SR, Richard AM, Adams SH, Corkey BE, O'Doherty RM, Brown NF: Increased beta-oxidation in muscle cells enhances insulin-stimulated glucose metabolism and protects against fatty acid-induced insulin resistance despite intramyocellular lipid accumulation. J Biol Chem 2004, 279:27177-27186.
14. Silveira LR, Fiamoncini J, Hirabara SM, Procopio J, Cambiagli TD, Pinheiro $\mathrm{CH}$, Lopes LR, Curi R: Updating the effects of fatty acids on skeletal muscle. J Cell Physiol 2008, 217:1-12.

15. Herr HJ, Bernard JR, Reeder DW, Rivas DA, Limon JJ, Yaspelkis BB: Insulinstimulated plasma membrane association and activation of Akt2, aPKC zeta and aPKC lambda in high fat fed rodent skeletal muscle. J Physiol 2005, 565:627-36.

16. Muhlhausler BS, Cook-Johnson R, James M, Miljkovic D, Duthoit E, Gibson R: Opposing effects of omega- 3 and omega- 6 long chain polyunsaturated fatty acids on the expression of lipogenic genes in omental and retroperitoneal adipose depots in the rat. J Nutr Metab 2010.

17. Buckley JD, Howe PRC: Anti-obesity effects of long-chain omega-3 polyunsaturated fatty acids. Obesity Rev 2009, 10:648-659.

18. Musa-Veloso K, Binns MA, Kocenas AC, Poon T, Elliot JA, Rice H, OppedalOlsen $H$, Lloyd $H$, Lemke S: Long-chain omega-3 fatty acids eicosapentaenoic acid and docosahexaenoic acid doese-dependently reduce fasting serum triglycerides. Nutr Rev 2010, 68:155-167.

19. Valencak TG, Ruf T: Feeding into old age: long-term effects of dietary fatty acid supplementation on tissue composition and life span in mice. J Comp Physiol B 2010.

20. Legrand P, Beauchamp E, Catheline D, Pedrono F, Rioux V: Short chain saturated fatty acids decrease circulating cholesterol and increase tissue PUFA content in the rat. Lipids 2010, 45:975-986.

21. O'Rahilly S, Farooqi IS: Human obesity as a heritable disorder of the central control of energy balance. Int J Obes (Lond) 2008, 32(Suppl 7): S55-S61.

22. Chagnon YC, Pérusse L, Weisnagel J, Rankinen T, Bouchard C: The human obesity gene map: the 1999 update. Obes Res 2000, 8:89-117.

23. Renne $U$, Bünger $L$, Schüler $L$ : Selection experiments for endurance and emotionality in mice -Direct selection response. Arch Anim Breed 1987, 30:321-328.

24. Renne U, Sumpf D, Herrendörfer G: Endurance fitness in a complete diallel cross among long-term selected mouse lines. Arch Anim Breed 1997, 40:483-490.

25. Brockmann G, Haley C, Renne U, Knott SA, Schwerin M: Quantitative trait loci affecting body weight and fatness from a mouse line selected for extreme high growth. Genetics 1998, 150:369-381.

26. Brockmann GA, Kratzsch J, Haley CS, Renne U, Schwerin M, Karle S: Single QTL effects, epistasis, and pleiotropy account for two-third of the phenotypic F2 variance of growth and obesity in DU6i $\times$ DBA/2 mice. Genome Res 2000, 10:1941-1957.

27. Brockmann GA, Haley CS, Wolf E, Karle S, Kratzsch Renne U, Schwerin N, Hoeflich A: Genome-wide search for loci controlling serum IGF binding protein levels of mice. FASEB J 2001, 15:978-987.

28. Calo MC, Vona G: Gene polymorphisms and elite athletic performance. $J$ Anthropol Sci 2008, 86:113-131.

29. MacArthur DG, Seto JT, Raftery JM, Quinlan KG, Huttley GA, Hook JW, Lemckert FA, Kee AJ, Edwards MR, Berman Y, Hardeman EC, Gunning PW, Easteal S, Yang N, North KN: Loss of ACTN3 gene function alters mouse muscle metabolism and shows evidence of positive selection in humans. Nat Genet 2007, 39:1261-1265.

30. Cauci S, Di Santolo M, Ryckman KK, Williams SM, Banfi G: Variable number of tandem repeat polymorphisms of the interleukin-1 receptor antagonist gene IL-1RN: a novel association with the athlete status. BMC Med Genet 2010, 22:11-29.

31. Dance LJE, Doran O, Hallett K, Dannenberger D, Nuernberg G, Nuernberg K: Comparison of two derivatisation methods for the conjugated linoleic acid isomer analysis by $\mathrm{Ag}^{+}-\mathrm{HPLC} / \mathrm{DAD}$ in beef fat. Eur J Lipid Sci Technol 2010, 112:188-194.

32. Miles JL, Huber K, Thompson NM, Davison M, Breier BH: Moderate daily exercise activates metabolic flexibility to prevent prenatally induced obesity. Endocrinology 2009, 150:179-186.

33. Hinney A, Vogel CIA, Hebebrand J: From monogenic to polygenic obesity: recent advances. Eur Child Adolesc Psychiatry 2010, 19:297-310.

34. Ntawubuzi M, Colman E, Janssens S, Raes K, Buys N, De Smet S: Genetic parameters for intramuscular fatty acid composition and metabolism in pigs. J Anim Sci 2010, 88:1286-1294.

35. Borkman M, Storlien LH, Pan DA, Jenkins AB, Chisholm DJ, Campbell LV: The relation between insulin sensitivity and the fatty-acid composition of skeletal muscle phospholipids. New Engl J Med 1993, 328:238-244. 
36. Kopecky J, Rossmeisl M, Flachs P, Kuda O, Brauner P, Jilkova Z, Stankova B, Tvrzicka Bryhn M: $n$-3 PUFA: bioavailability and modulation of adipose tissue function. Proc Nutr Soc 2009, 68:361-369.

37. Power GW, Newsholme EA: Dietary fatty acids influence the activity and metabolic control of mitochondrial carnitine palmitoyltransferase I in rat heart and skeletal muscle. J Nutr 1997, 127:2142-2150.

38. Das UN: Obesity: Genes, brain, gut, and environment. Nutrition 2000 26:459-473.

39. Wood JD, Enser M, Fisher AV, Nute GR, Sheard PR, Richardson RI, Hughes SI, Whittington FM: Fat deposition, fatty acid composition and meat quality: A review. Meat Sci 2008, 78:343-358.

40. Sanz Sampelayo MR, Fernandez Navarro JR, Hermoso R, Gil Extremera F, Rodriguez Osorio M: Thermogenesis associated to the intake of a diet non-supplemented or supplemented with $n-3$ polyunsaturated fatty acid-rich fat, determined in rats receiving the same quantity of metabolisable energy. Ann Nutr Metab 2006, 50:184-192.

41. Prentice A, Jebb S: Fast foods, energy density and obesity: a possible mechanistic link. Obesity Rev 2003, 4:187-194.

42. Jobgen W, Meininger CJ, Jobgen SC, Li P, Lee M-J, Smith SB, Spencer TE, Fried SK, Wu G: Dietary L-arginine supplementation reduces white fat gain and enhances skeletal muscle and brown fat masses in dietinduced obese rats. J Nutr 2009, 139:2300-2237

43. Roberts R, Bickerton AS, Fielding BA, Blaak EE, Wagenmakers AJ, Chong MFF, Gilbert M, Karpe F, Frayn KN: Reduced oxidation of dietary fat after a short term high-carbohydrate diet. Am J Clin Nutr 2008, 87:824-831.

44. Jackman MR, Kramer RE, MacLEan PS, Bessesen DH: Trafficking of dietary fat in obesity-prone and obesity-resistant rats. Am J Physiol Endocrinol Metab 2006, 291:E1083-E1091.

45. Soukas AA, Kane EA, Carr CE, Melo JA, Ruvkun G: Rictor/TORC2 regulates fat metabolism, feeding, growth, and life span in Caenorhabditis elegans. Genes Dev 2009, 23:496-511.

46. Jump DB: Dietary polyunsaturated fatty acids and regulation of gene transcription. Curr Opin Lipidol 2002, 13:155-164.

47. Levy JR, Clore JN, Stevens W: Dietary n-3 polyunsaturated fatty acids decrease hepatic triglycerides in Fischer 344 Rats. Hepatology 2004, 39:608-616.

48. Flachs $P$, Horakova $O$, Brauner $P$, Rossmeisl M, Pecina P, Franssen-van Hal N, Ruzickova J, Sporanova J, Drahota Z, Vlcek C, Keijer J, Houstek J, Kopecky J: Polyunsatured fatty acids of marine origin upregulate mitochondrial biogenesis and induce $\beta$-oxidation in white fat. Diabetologica 2005, 48:2365-2375.

49. Sampey BP, Vanhoose AM, Winfield HM, Freemerman AJ, Muehlbauer MJ, Fueger PT, Newgard CB, Makowski L: Cafeteria diet is a robust model of human metabolic syndrome with liver and adipose inflammation: comparison to high-fat diet. Obesity 2011.

50. Perez-Matute P, Perez-Echarri N, Martinez A, Marti A, Moreno-Aliaga MJ: Eicosapentaenoic acid actions on adiposity and insulin resistance in control and high-fat-fed rats: role of apoptosis, adiponectin and tumour necrosis factor-a. Br J Nutr 2007, 97:389-398.

51. Galgani JE, Uauy RD, Aguirre CA, Diaz EO: Effects of the dietary fat quality on insulin sensitivity. Brit J Nutr 2008, 100:471-479.

52. de Wilde J, Smit E, Mohren R, Boekschoten MV, de Groot P, van den Berg SA, Bijland S, Voshol PJ, van Dijk KW, Bunschoten A, Schaart G, Hulsdorf MF, Mariman EC: An 8-week high-fat diet induces obesity and insulin resistance with small changes in the muscle transcriptome of C57BL/6J mice. J Nutrigenet Nutrigenomics 2009, 2:280-291.

53. Poureslami R, Raes K, Huyghebaert G, De Smet S: Effects of diet, age and gender on the polyunsaturated fatty acid composition of broiler anatomical compartments. Br Poult Sci 2010, 51:81-91.

54. Leaver MJ, Taggart JB, Villeneuve L, Bron JE, Guy DR, Bishop SC, Houston RD, Matika O, Tocher DR: Heritability and mechanisms of n-3 long-chain polyunsaturated fatty acid deposition in the flesh of Atlantic salmon. Comp Biochem Physiol Part D Genomics Proteomics 2011, 6:62-69.

55. Lemaitre RN, Siscovick DS, Berry EM, Kark JD, Friedlander Y: Familial aggregation of red blood cell membrane fatty acid composition: the Kibbutzim family study. Metabolism 2008, 57:662-668.

56. Mitchell TW, Buffenstein R, Hulbert AJ: Membrane phospholipid composition may contribute to exceptional longevity of the naked mole-rat (Heterocephalus glaber): A comparative study using shortgun lipidomics. Exp Gerontol 2007, 42:1053-1062.
57. Saito M, Kubo K: Relationship between tissue lipid peroxidation and peroxidability index after a-linolenic, eicosapentaenoic, or docosahexaenoic acid intake in rats. Br J Nutr 2003, 89:19-28.

doi:10.1186/1743-7075-8-56

Cite this article as: Nuernberg et al:: Metabolic responses to high-fat diets rich in $n-3$ or $n-6$ long-chain polyunsaturated fatty acids in mice selected for either high body weight or leanness explain different health outcomes. Nutrition \& Metabolism 2011 8:56.

\section{Submit your next manuscript to BioMed Central and take full advantage of:}

- Convenient online submission

- Thorough peer review

- No space constraints or color figure charges

- Immediate publication on acceptance

- Inclusion in PubMed, CAS, Scopus and Google Scholar

- Research which is freely available for redistribution

Submit your manuscript at www.biomedcentral.com/submit
C Biomed Central 